\title{
PEQUEÑAS CONQUISTAS EN LA ADVERSIDAD: POSIBILIDADES DE AGENCIA DE MUJERES QUE USAN LA VIOLENCIA EN BUENOS AIRES Y TRABAJADORAS SEXUALES EN LA FRONTERA SUR DE MÉXICO
}

\author{
María Antonieta Beltrán Savenije \\ FLACSO Argentina \\ Laura Aguirre \\ Instituto de Estudios Latinoamericanos \\ Freie Universität Berlin
}

\section{RESUMEN}

El presente artículo busca visibilizar las posibilidades de agencia que algunas mujeres tienen incluso cuando viven en limitadas condiciones sociales que restringen sus acciones y que las pueden llevar a sufrir victimización. Con base en dos investigaciones cualitativas: 1) mujeres de barrios populares del conurbano bonaerense que utilizan violencia (2008-2010), y 2) migrantes centroamericanas trabajadoras en el comercio sexual de la frontera sur de México (2011-2013), se muestra su capacidad para tomar decisiones y actuar. Esto se evidencia, en el caso de mujeres que usan violencia, en que saben pelear, defender a otros, impedir que las asalten o forjarse una reputación; en el caso de las migrantes, en mantenerse acompañadas, negociar sus servicios y pagos, huir de las autoridades y trabajar en la calle en lugar de hacerlo en bares.

PALABRAS CLAVE

Víctima, Agencia, Violencia de género, Trabajadoras sexuales, Migrantes, Mujeres que usan violencia

\section{ABSTRACT}

This article seeks to visualize the possibilities of agency that some women have even if they live in social limited conditions that restrict their actions and even put them in danger of suffering victimization. Based in two qualitative researchs: 1) women from slums of Buenos Aires' outskirts (2008-2010), and 2) Centralamerican migrants sex workers in the Mexican Southern border (2011-2013), we show their capability of taking decisions, and act. This becomes visible when they show they can fight, defend other people, prevent an assault or establish a reputation in the case of women that use violence, and 
to look for company, negotiate their services and payment, to run away from authorities and to work in the streets instead of bars, in the case of the migrants.

KEY WORDS

Victim, agency, Gender violence, Sex workers, Migrants, Women that use violence 


\section{INTRODUCCIÓN}

El binomio mujeres y violencia evoca con frecuencia la imagen de una mujer que ha sido víctima de abusos y ha sufrido daños. En efecto, el espectro de mujeres en esa situación es muy amplio (Krantz y Garcia-Moreno, 2005).

Dentro de la lucha por los derechos humanos de las mujeres, la categoría víctima se ha erigido como la estrategia principal para concientizar sobre las distintas formas de violencia que éstas sufren y, además, como la posición legítima para reclamar derechos. Al respecto, Kapur afirma que "el sujeto víctima ha permitido a las mujeres hablar sobre los abusos que habían permanecido ocultos o invisibles en el discurso sobre los derechos humanos" (Kapur, 2002: 5).

Indudablemente, la visibilización de la víctima ha traído diversos beneficios a las mujeres. Pero al mismo tiempo, la exclusividad que se le ha dado a la exposición de las realidades de violencia ha ensombrecido las luchas y resistencias cotidianas de las mujeres. Como señala Agustín, "el problema es que la persona designada como víctima tiende a tomar una identidad de víctima que la reduce a ser vista como un receptora pasiva" (Agustín, 2003: 1).

Este artículo trae a cuenta dos ejemplos en los que mujeres de dos países latinoamericanos, expuestas a situaciones de riesgo y violencia, conservan la capacidad de enfrentar este tipo de circunstancias en su vida diaria, pudiendo incluso cambiarlas o mejorarlas en función de sus preocupaciones e intereses personales. A partir de los datos generados con ambas investigaciones, se busca complejizar el uso de la categoría víctima y resaltar la agencia. Para ello se sigue a Mahmood
(2001), que entiende la agencia como la capacidad de actuar creada y potenciada por relaciones históricas de subordinación; es decir, dentro de estructuras sociales que limitan y al mismo tiempo propician las acciones de las mujeres. De esta manera se expone la compleja y paradójica articulación de la agencia humana incluso cuando su margen de acción se ve limitado por las múltiples condiciones sociales y estructurales que restringen sus posibilidades.

Metodológicamente, los dos estudios que se exponen son de corte cualitativo y utilizaron el método etnográfico.

El primero es un trabajo sobre mujeres habitantes de dos barrios populares del conurbano de Buenos Aires, Argentina, realizado entre mayo de 2008 y abril de 2010. Se trata de lugares a los que se imputa una manifestación visible y frecuente de sucesos violentos. A pesar de que en dichos entornos la violencia es ejercida predominantemente por hombres, algunas mujeres también recurren a la fuerza física como una forma de ir sorteando sus dificultades cotidianas. Con este ejemplo se busca mostrar que mujeres que sufren diferentes abusos o violencia en situaciones específicas, también están en la posibilidad de ejercer su agencia para pelear y mostrar que pueden cuidarse solas, defender a sus seres queridos de agresiones, impedir que las asalten e incluso ayudarles a formarse una reputación.

El segundo aborda el caso de mujeres migrantes que trabajan en el comercio sexual en Tapachula y Ciudad Hidalgo, en la frontera sur de México. La información fue recolectada durante siete meses de trabajo de campo repartidos entre 2011 y 2013. Debido al estigma que conlleva el trabajo sexual, sumado a la condición de género, de clase, estatus 
migratorio y nacionalidad, estas mujeres ocupan una posición de alta vulnerabilidad a abusos y violaciones de sus derechos humanos. Sin embargo, dentro de estas condiciones constrictivas las mujeres logran hacer valoraciones, tomar decisiones y actuar para protegerse y obtener algunos beneficios. Esto lo hacen buscando ir acompañadas (y, por tanto, nunca solas) cuando se alejan de su lugar de trabajo, negociar con anticipación sus servicios y pago, huir de las autoridades y trabajar en la calle en lugar de hacerlo en bares establecidos.

El siguiente apartado inicia con una síntesis del marco conceptual de la violencia contra la mujer y la victimización desde el patriarcado, para luego exponer el acercamiento teórico a las categorías víctima y agente, mismas desde la que se plantean los estudios de este artículo. Después de exponer ambas investigaciones, y a la luz de este material empírico, se finaliza con una reflexión sobre la ambivalencia de la víctima y la agente.

\section{EL SISTEMA PATRIARCAL}

\section{Y LA VIOLENCIA DE GÉNERO}

El patriarcado es el marco principal dentro del cual se ha analizado la violencia contra las mujeres. Desde esta perspectiva, la estructura patriarcal propicia que el género se constituya de manera jerárquica como el resultado de un proceso de construcción social desigual en el que los hombres tienen una posición hegemónica y de dominación (Bergalli y Bodelón, 1992; Hartsock, 1992; Pateman, 1995). Esto posibilita distintas formas de violencia que van desde manifestaciones sutiles de poder hasta recurrir a la violencia física (Maqueda, 2006: 4). Este análisis se fundamenta en dos representaciones sociales dominantes: el hombre como perpetrador de la violencia machista y la mujer como la víctima legítima. Dichas construcciones sociales están en la base de la producción de conocimiento sobre la problemática y en la organización de las prácticas que atienden a las destinatarias de las diferentes manifestaciones de violencia.

La violencia contra la mujer fue definida en la Plataforma de Acción de Pekín como "todo acto de violencia basado en el género que tiene como resultado posible o real un daño físico, sexual o psicológico, incluidas las amenazas, la coerción, o la privación arbitraria de libertad". Pero además especifica que la violencia masculina contra las mujeres jóvenes y adultas tanto en la familia como en el lugar de trabajo o en la sociedad o en el Estado incluye, entre otros, los malos tratos, las agresiones físicas, las mutilaciones genitales y sexuales, el incesto, el acoso sexual, el abuso sexual, la trata de mujeres y la violación (Cuarta Conferencia Mundial de la ONU sobre la Mujer, 1995). Es decir, incluyó aspectos que previamente se justificaban en nombre de la cultura, la tradición y las estructuras económicas.

El planteamiento de la plataforma de Pekín es el que se ha difuminado a escala global para abordar la violencia de género. Esta definición toma al patriarcado como el marco explicativo y al hombre como maltratador de la mujer. La violencia se entiende entonces como una herramienta para mantener el status quo masculino.

No obstante, esta conceptualización ha sido ampliamente criticada con base, al menos, en los siguientes argumentos: a) explicar la violencia contra las mujeres desde el patriarcado tiene el 
peligro de producir representaciones esencialistas de la "mujer", del "hombre" y del "patriarcado" (Suárez-Navaz, Martín y Hernández, 2008a); b) homogeniza las experiencias de todas las mujeres (Brewer, 1999); c) invisibiliza la intersección de otras formas de poder, como la clase y la razaetnicidad, en la formas de violencia hacia las mujeres (Mohanty, 2003); y d) el patriarcado aparece como estático en la historia (García Selgas y Casado Aparicio, 2010; Ravelo Blancas, 2001).

Siguiendo esa línea, representantes del feminismo negro, poscolonial y transnacional introdujeron una perspectiva crítica a los planteamientos occidentales sobre el sujeto "mujer" como víctima universal de la violencia de género y la emancipación. Desde esta perspectiva, la violencia de género no se puede entender sin las opresiones de raza, clase y sexualidad, las cuales funcionan como una amalgama indisoluble (Brewer, 1999; Mohanty, 2003). Por tanto, el problema de utilizar la categoría "víctimamujer" en sentido universal, definida a través del patriarcado y sin el reconocimiento de las otras relaciones de poder es que la lógica categorial termina visibilizando solamente las opresiones de la representación dominante, mujeres de pieles claras de clase media, heterosexuales o todas aquellas que se ajusten a ese molde. Como resultado se genera un oscurecimiento de la violencia de género fuera de la lógica occidental (Lugones, 2008).

1 Las críticas incluyen a otras subjetividades más allá del binomio heteronormativo hombre-mujer. Se reconoce que la categoría mujer es parte de un dispositivo de género más amplio; sin embargo, en el presente artículo se acota el análisis a la construcción de la mujer del tercer mundo frente a la mujer occidental.
No obstante, la explicación predominante a la violencia de género sigue priorizando casi exclusivamente al sistema patriarcal. Así, en la lucha por su erradicación se ha llegado a un enfoque unidimensional (Nayak y Suchland, 2006; Weseley, 2006) con un marcado énfasis en su victimización y opresión de las mujeres, ocultando sus fortalezas (Hollander, 2005). En consecuencia, en las discusiones sobre violencia y género, se ha llegado a ver la victimización como un atributo de la feminidad (Hollander, 2002, 2005), dejando de lado sus formas de resistencia y sus intentos de cambiar sus situaciones de opresión o abuso.

\section{La construcción discursiva \\ de "la víctima" y "la agente"}

La categoría "víctima" es una construcción compleja, cuya definición puede abarcar varios significados. La más recurrente es la que designa a las personas afectadas por actos criminales y con frecuencia se la equipara a la figura de la "víctima ideal" (Christie, 1986), definida como "una persona o individuos que —al ser afectado(s) por un crimen - reciben el completo y legítimo estatus de ser una víctima" (Smolej, 2010: 67). Esta víctima se identifica por ciertos atributos: es débil en relación con el perpetrador, con frecuencia es una mujer, un enfermo, una persona muy vieja o una muy joven, que estaba realizando alguna labor cotidiana y respetable al momento del crimen; mientras que el perpetrador es malo, más grande y fuerte, casi siempre hombre (Dignan, 2004). La "víctima ideal" es absolutamente inocente y pasiva ante la situación que le causó daño. A pesar que se ha reconocido la brecha que existe entre esta 
construcción social y la realidad de las personas que son objeto de violencia, sigue siendo una referencia en los discursos, entre ellos el de la violencia contra la mujer (Randall, 2004).

Esta concepción de la "víctima", utilizada también por una parte del feminismo occidental tradicionalmente blanco y liberal, ha sido fuertemente contestada. A pesar de la utilidad que ha tenido para evidenciar la violencia y los abusos de hombres hacia mujeres y conseguir los beneficios que ha traído cuando se utiliza como una posición desde la cual exigir derechos y la persecución de los "perpetradores", también se ha señalado cómo la mujer ha terminado por adquirir la identidad del sujeto de dominación que se personifica en "la víctima". De los individuos que encarnan esta representación, se esperará, entonces, cierta conducta, forma de expresarse y sentirse. Entonces, en tanto víctimas, las mujeres reciben la solidaridad y la simpatía social, pero también denotan una visión de la mujer inherentemente vulnerable, pasiva y con poca o nula capacidad de agencia y resistencia (Dunn, 2005; Dunn y Powell, 2007: 978).

Mohanty $(1991,2003)$ expuso cómo en el discurso académico feminista occidental las mujeres del "tercer mundo" han sido representadas como víctimas manifiestas de la ideología y sistema patriarcal. Este discurso retomado por organizaciones internacionales y gobiernos nacionales, ha tenido como consecuencias principales la generalización de las mujeres del "tercer mundo" como sujetos vulnerables, carentes de cualquier tipo de poder. Por consiguiente, se ha tendido a ignorar y silenciar las experiencias reivindicativas de muchas mujeres fuera de las fronteras de lo que se considera "el primer mundo" al catalogarse tales experiencias como la expresión de una falsa conciencia y, por tanto, como parte inherente de su victimización (McClintock, 1993).

Central en el debate, a partir de la segunda ola feminista, ha sido también la cuestión de la agencia de las mujeres. Aunque las posiciones al respecto son múltiples, una de las más conocidas en torno a las posibilidades de acceso al poder se centra en la figura de "la agente" como mujer emancipada y empoderada para transformarse a sí misma y, desde ahí, al sistema de dominación masculina (Allen, 2001). De esta manera, la preocupación feminista pasa de la relación de dominación-subordinación a destacar las condiciones que habilitan a las mujeres para formular y llevar a cabo acciones motivadas por sus intereses y encaminadas a conseguir sus metas personales. Así, se ha producido un sujeto femenino cuya capacidad de actuar es resultado de decisiones individuales, tomadas de forma autónoma y libre.

La crítica principal a esta manera de pensar la agencia es que su planteamiento es muy simple. Allen (2001) ha señalado que los enfoques que enfatizan la agencia como empoderamiento y emancipación suelen presumir que las posibilidades de acción y transformación de las mujeres sobre la dominación masculina son demasiado sencillas. El efecto principal es que se crea, al igual que con "la víctima", un sujeto "agente" estático como si de una identidad fija se tratara (Sánchez, 1999), y se oscurecen las maneras en que la agencia y el empoderamiento están implicados en la reproducción de las estructuras sociales.

Tanto "la agente" como "la víctima", en cuanto representaciones ideales de la dicotomía 
dominación-empoderamiento, han sido tomadas y construidas muchas veces como condiciones mutuamente excluyentes (Connell, 1997; Dunn y Powell, 2007). Esta clase de oposiciones dejan de lado los traslapes entre ser víctima y agente (Dunn y Powell, 2007; Brunatti, 2011) y dificultan la comprensión de las maneras complejas en que las mujeres pueden ser víctimas y agentes al mismo tiempo (Allen, 2008).

Con el objetivo de ir más allá de las limitaciones que supone el binomio víctima/agente, usamos como lente analítico la propuesta teórica sobre la agencia de Mahmood (2001), quien toma como punto de partida la concepción de poder que propone Butler. Esta autora plantea el poder como un conjunto de relaciones que no solo implican la dominación del sujeto, sino también las condiciones de su existencia (Butler, 1999, 2001), a lo que la propia Butler denomina la paradoja de la sujeción. Lo anterior conjunta los procesos y las condiciones que aseguran la subordinación del sujeto y al mismo tiempo en el medio a través del cual adquiere (el sujeto) una toma de conciencia de identidad y de agencia. Esta última por tanto no se edifica como algo externo y previo a los dispositivos de poder, sino como producto de éstos. Desde esta concepción de poder y sujeto, la agencia implica no solo la resistencia y oposición a los sistemas de dominación, sino también la capacidad de acción que estos sistemas crean y potencian. Mahmood concuerda con Butler en ubicar la constitución de las posibilidades de resistencia dentro de las estructuras de poder y no en la toma de conciencia del individuo autónomo y libre. Sin embargo, amplía esta propuesta al plantear que la agencia no solo puede tomar la forma de subversión u oposición a las normas, ni tener siempre objetivos políticos emancipadores. La agencia para esta autora es una modalidad de acción amplia que implica la habilidad de hacer pequeños cambios en el mundo y en una misma dentro de condiciones históricas y culturales específicas. Estas acciones incluyen modos específicos de ser, la afectividad, las aspiraciones, los proyectos y deseos. Afirma:"Visto de esta manera, lo que puede parecer un caso de deplorable pasividad desde un punto de vista progresista, puede muy bien ser una forma de agencia, una que debe ser entendida dentro del contexto de los discursos y estructuras de subordinación que crean las condiciones de su promulgación" (Bluter, 2001: 212).

En este artículo se entiende "la víctima" $y$ "la agente" no como categorías que designan identidades fijas y excluyentes, sino como categorías relacionadas, fluidas y que denotan constante negociación. La víctima hace referencia a momentos específicos en los que las mujeres, por su condición de género, clase, raza o nacionalidad, han sufrido abusos o daños físicos y psicológicos (Cuarta Conferencia Mundial de la ONU sobre la Mujer, 1995). Frente a estas situaciones, sin embargo, las mujeres conservan la capacidad de decidir, de actuar y hacerse responsables de estas acciones. Esta habilidad significa "la capacidad de pensar, elegir y operar dentro de los sistemas de poder de acuerdo a los acontecimientos de la vida cotidiana"2 (Sussman, 2008: 15). Estas acciones estarán mediadas por los

2 En su revisión sobre el concepto de agencia, Emirbayer y Mische (1998) afirman que todos los intentos de teorizarla omiten aspectos importantes de la misma. Desde su punto de vista, el feminismo ha puesto demasiado énfasis en la toma de decisiones y la capacidad de juzgar. 
contextos históricos, socio-políticos y económicos y por los límites impuestos por las convenciones sociales y recursos de los que dispongan (Young, 2011). Una mujer agente, por tanto, no terminará necesariamente con la dominación de la que es objeto, ni sus acciones corresponderán siempre a las conductas esperadas para una mujer emancipada.

Por ejemplo, en situaciones en las que hay grandes riesgos de sufrir violencia, huir no es forzosamente la mejor respuesta. A veces, quedarse o ir a lugares donde existe el riesgo de ser victimizadas es para ellas la mejor opción (véase Dunn y Powell, 2007). Algunas mujeres, incluso, logran negociar con sus maltratadores cuando éstos ejercen un control coercitivo constante, o eligen usar violencia física en contra de ellos. También algunas mujeres deciden emigrar en condiciones desfavorables y hacer trabajos que no les gustan ni han hecho antes, pero que les permiten obtener mejores ingresos y acercarse a lo que consideran una mejor vida. Estas acciones pueden considerarse maneras de agencia en tanto responden a las decisiones de las mujeres que las habilitan para lidiar con las situaciones de opresión en momentos concretos, aun cuando ésas no supongan la subversión de su subordinación. Eso no implica que en medio de esas elecciones las mujeres eliminen el riesgo de seguir siendo golpeadas, abusadas, controladas a través de la economía y las relaciones familiares o laborales, $\mathrm{o}$ que sus acciones reproduzcan de hecho el sistema de dominación. Sufrir victimización, pero también tomar decisiones, actuar y resistir pueden ocurrir simultáneamente (Kelly, 1995, en Connell, 1997).

\section{MUJERES AMBIVALENTES}

A continuación se presentan dos casos que desafían los límites de la dicotomía víctima/agente y revelan la ambivalencia que caracteriza la relación entre ambas categorías. Con base en la narrativa de mujeres habitantes de barrios populares que utilizan violencia (Beltrán, 2013) ${ }^{3}$ y migrantes centroamericanas que trabajan en el comercio sexual de la frontera sur de México ${ }^{4}$, se evidencia, por una parte, cómo, aun en situaciones de gran vulnerabilidad, las mujeres son capaces de llevar a cabo acciones, resolver problemas y tomar decisiones; y por otra, la complejidad de las experiencias vividas. Es decir, situaciones en las que la opresión y la agencia no son posiciones estáticas, ni identidades fijas que denotan si los sujetos son dominados o libres; más bien se trata de una dinámica relacional en la que "la víctima" y "la agente" toman formas culturales y sociales fluidas (Allen, 2001) que se encarnan en los sujetos.

\section{Caso 1: violencia practicada por mujeres}

La revisión de literatura sobre violencia (y delitos) cometida por mujeres muestra que ésta puede presentarse en distintos contextos y clases sociales (véase Batchelor, 2005; Campbell, 1999; Chesney-Lind y Eliason, 2006; Wesely, 2006). Los barrios populares no son un lugar exclusivo de su manifestación y se les reconoce como lugares donde

3 Tesis doctoral "Construcciones localizadas de la identidad de género: usos legítimos e ilegítimos de la fuerza en mujeres de barrios populares urbanos" (2013). Universidad de Buenos Aires. La metodología consistió en observación participante, entrevistas a informantes clave e historias de vida.

4 Investigación realizada en el marco del proyecto de doctorado "La prostituta de la frontera: tácticas cotidianas de resistencia de las mujeres que trabajan en el comercio sexual de la franja fronteriza sur de México" (Aguirre, investigación en curso, Freie Universität Berlin). 
no sólo se presentan la violencia, sino también la criminalidad, la pobreza, ruptura de lazos sociales, fragmentación, abandono institucional, e incluso, abuso policial (Puex, 2003). La vida callejera de los barrios visitados se organiza bajo el "código de la calle". Este consiste en "una serie de reglas que gobiernan la conducta interpersonal pública, particularmente la violencia" (Anderson, 1999: 33). En el centro del código está la noción de respeto, es decir, "ser bien tratado o recibir lo que es propiamente debido o la deferencia que uno merece" (Anderson, 1999: 33). Saber defenderse en la calle, resistir, defender a sus pares, no temer y ser temido por los demás, son todas formas de respeto (Anderson, 1999).

La facilidad para observar e interactuar en la vida cotidiana con sus habitantes determinó que de manera general los barrios populares fuesen los escenarios escogidos para la investigación. Los barrios fueron seleccionados a partir del acceso que se pudo tener a ellos a través de instituciones que realizaban trabajo social in situ y fue a través de estas instituciones que se iniciaron los contactos con sus habitantes. Durante el primer año se realizó únicamente observación participante, a partir de la cual se escogió a ocho entrevistadas (cuatro por barrio) para las historias de vida. ${ }^{5}$ Las participantes

5 Se hicieron cuatro entrevistas con cada una de las ocho informantes con las que se construyeron las historias de vida. Sus edades oscilaban entre los 27 y 36 años. También se realizaron seis entrevistas a informantes clave, tres por barrio. En total, se obtuvo 40 entrevistas. Las historias de vida retomaron aspectos que llevaban a identificar conflictos, manifestaciones de violencia física y verbal presentes en el hogar, la escuela y la comunidad; también en las formas pasadas $\mathrm{y}$ actuales de educar o corregir, la interacción entre padres e hijos, entre las mujeres y su pareja, así como los posibles asaltos y robos, y las riñas en el barrio sólo entre hombres, fueron seleccionadas porque se observaron en ellas prácticas de violencia que se han categorizado como formas de agencia, entre las que cabe mencionar: a) mostrar que saben pelear y cuidarse; b) defender a sus seres queridos c) obtener el reconocimiento o respeto por parte de sus vecinos; y d) impedir asaltos y tener represalias cuando lo intentan. Estas cuatro manifestaciones se revisan a continuación.

En los barrios populares, la violencia suele presentarse entre hombres que se amenazan o agreden entre ellos siguiendo el "código de la calle". Sin embargo, las mujeres, también tienen motivos para preocuparse de las amenazas de diversas agresiones cuando circulan por el barrio. Ellas también pueden ser sujeto de provocaciones o invitaciones a pelear por parte de otras mujeres. Por tanto, deben mostrar que no están dispuestas a dejarse intimidar y que saben hacerse respetar. Dos de las entrevistadas ${ }^{6}$ lo confirmaron así:

Si me joden y me pegan otros, tendré que pegar. Si no me pegan no; pero de lo contrario sí... Acá te atacan. No te invitan a pelear, vienen y te arrebatan si quieren pelear. No te dejan decir ni hola. Así se usa acá, entonces una tiene que estar así, alerta (Josefina, 30 años).

Aquí si no te paras de manos [posición de pelea], no existís. Sos un cagón [miedoso]. Te tenés que parar de manos. No se trata de poner la otra mejilla [risas]... Y lo hacen más las adolescentes (Lorena, 25 años).

Esos ejemplos muestran maneras en que las mujeres se mueven en el barrio y comunican que pueden cuidarse ellas mismas. El mensaje para

sólo entre mujeres, o indistintamente del género y la edad. 6 Los nombres de todas las entrevistadas han sido cambiados para preservar el anonimato de las entrevistadas. 
el entorno es que saben pelear y que es mejor dejarlas tranquilas. Para sus protagonistas, son formas de responder y de prevenir nuevas amenazas, construyendo una reputación. Cuando se trata de adolescentes, el reconocimiento de que saben pelear les da una amplia notoriedad entre sus pares. Ellas buscan ser percibidas como buenas peleadoras, como lo muestran las siguientes citas:

¡Aquí hubo cada ring! La gente como que festeja, se pone como cuando pelean los boxeadores y grita: 'Dale más, dale así'. Con que gane la que gane, por cualquier pelea, ya uno va sabiendo quiénes son las que pelean. A ellas les gusta eso de ser 'la más mala del barrio' (Isabel, 36 años).

-Aquí las pibas andan todas en patota [grupo]. Ellas son fuertes en patota, solas no. La mayoría de las pibas de acá no pueden pisar otro barrio [distinto al de ellas] solas porque buscan quilombo [problemas] en todos lados.

-¡Ah! ¿Entonces si andan solas otras se desquitan?

-Sí, así es aquí, a revanchar o a revanchar.

-Pero siempre en grupo.

-Sí, les gusta el quilombo, decir "yo la maté", pero en grupo (Ada, 27 años).

Tener un público que las observe y vitoree cuando pelean es primordial para obtener fama de ser la mejor peleadora o "la más mala del barrio". Medirse con otra adolescente que tenga reputación en el barrio es una forma de buscarse reconocimiento. Pero no siempre las peleas quedan solo entre mujeres; a veces ellas intervienen también cuando hay hombres de por medio. Si juzgan que una riña entre hombres te torna desigual o peligrosa para alguno de los contrincantes, las mujeres adultas _ parientes de los involucrados_ salen a las calles a defender a sus seres queridos. Algunas relatan cuando les ha sucedido esa situación:

Me ha pasado que me he metido en quilombos por mi hermano: mi hermano peleando y yo metida en el medio. Tratando de protegerlo me cagaron a patadas a mí; no me mataron de pedo [de casualidad]. En ese momento es tal la adrenalina que te lleva que no te das cuenta. Una guerra campal fue ese día. Lo de mi hermano fue todos contra todos [...] Mujeres, chicos, grandes, de todo (Daniela, 30 años).

Las riñas las empiezan más chicos jóvenes. Son chicos contra chicos y se les agregan familiares de los que se están peleando y son mujeres. Atrás de mi casa se pelean banda con banda, son todos hermanos los de un grupo y todos amigos los del otro grupo. Saltan entre todos y las hermanas de la otra familia se meten a ayudar a los hermanos a tirar patadas, piñas [golpes] (Isabel, 36 años).

La defensa de los hijos e hijas y las peleas callejeras de las madres son una dinámica constatada a menudo en los barrios visitados. En esas ocasiones, el uso de fuerza física contra otros es valorado como lícito por los residentes del barrio, e incluso otorga reconocimiento a las madres, pues muestran que son capaces de todo por sus hijos. Al defenderlos se muestran como buenas madres o mujeres protectoras.

Una forma más en la que recurrir a la violencia se torna útil para estas mujeres es la defensa de asaltos y las represalias por los mismos, como lo muestran los siguientes ejemplos:

Una vez me quisieron asaltar cuando yo cumplí 15 años. Mi primo me compró una cadena muy, muy finita, y me regaló un premio [colgante] [...] Yo estaba 
en la parada del colectivo. Y viene un chico como si nada, y me miraba, me miraba la cadenita. Cuando se me acerca y me agarra así [movimiento para sacarle la cadena], yo enseguida le agarré la mano. Alcanzó a agarrarme la cadena y me la rompió, pero no me la sacó. Entonces cuando yo lo agarré de la mano, me quiso manotear pero yo lo agarré de los pelos y lo tiré al piso [...], yo le había puesto la rodilla en la cara [...] Hasta que la soltó (Berta, 28 años).

En un intento de robo, un pibe trató de arrancar a Esmeralda la bolsa que llevaba en las manos. Ella iba con su hija en brazos y se resistió [...] El chico se fue. Semanas después, Esmeralda iba caminando para hacer compras. De pronto vio al pibe que le quiso robar. Él también la miró y se dio la vuelta haciéndose el loco. Pero ella al reconocerlo fue tras él, lo tomó del hombro, lo hizo girar, lo lanzó al suelo y empezó a darle golpe tras golpe. 'Esto es por haberme querido robar, encima cuando estaba con mi hija' contó que le decía (Notas de campo).

En este caso, recurrir a la fuerza física tiene la utilidad de evitar robos y distintos agravios, al mismo tiempo que se gana respeto. Vale aclarar que muchas mujeres no están interesadas necesariamente en destacarse por sus habilidades de pelear y no buscan la confrontación; no obstante, tampoco están dispuestas a ser sujetos de golpes, desahogos o robos. Tampoco están dispuestas a tolerar que sus hijos, hijas u otros familiares sean golpeados en una riña; defenderlos peleando les otorga el reconocimiento de mujeres buenas y protectoras.

\section{Entre la victimización y la agencia}

en los barrios populares

Para entender la manera en que las mujeres usan violencia es necesario comprender sus circunstancias sociales, materiales y genéricas, es decir, cómo las mujeres viven sus vidas y cómo dan sentido a sus acciones (Batchelor, 2005; ChesneyLind y Pasko, 2004). Muchas de las mujeres que recurren a la fuerza física viven en lugares donde la (amenaza de) violencia está omnipresente, en las calles y en las casas (Campbell, 1993, 1999; Chesney-Lind y Hagedorn, 1999; Chesney-Lind y Jones, 2010; Jones, 2010; Ness, 2010). Saben que para sobrevivir en esos ambientes donde corren un riesgo elevado de ser amedrentadas, golpeadas o asaltadas, la fuerza y la amenaza de su uso resultan ser buenas herramientas.

Los estudios de género centrados en los usos de violencia de mujeres - principalmente anglosajones - resaltan las condiciones de precariedad que las rodean (véase, Chesney-Lind, y Pasko, 2004; Jones, 2010; Miller, 2001; Ness, 2010). En ellos se señala que la estructura patriarcal, unida a la situación de marginalidad en la que ellas viven, las coloca en una situación de doble vulnerabilidad: la de ser mujeres y la de vivir en lugares peligrosos. Muchas mujeres que se la pasan en la calle han sido victimizadas en sus casas, y las condiciones en las que viven las obligan a optar por la violencia para defenderse. Es estos casos, son ubicadas una vez más en una situación de victimización, incluso cuando actúan de manera violenta (Miller, 2001). Esta perspectiva prioriza la estructura patriarcal universal, sin tener en cuenta la estructura del barrio que posibilita y permite el uso de la violencia en mujeres, siendo ésta una manifestación de su agencia (Beltrán, 2013).

En su cotidianidad, las mujeres de barrios populares se ven frente a constantes elecciones: 
pueden mostrarse pasivas o miedosas; dejar que las ataquen y roben, encerrarse en sus casas; o actuar, recurriendo al uso de fuerza (Hollander, 2002; Jones, 2010). En esos barrios, el uso de fuerza física es aceptado, también para las mujeres, jóvenes o adultas, madres e hijas. Así, dar golpes para resistir o defenderse y defender a otros no es visto como una conducta impropia de las mujeres; se trata de una manera de enfrentar las condiciones presentes en su barrio (Beltrán, 2013).

Cuando toman la decisión de no permitir que las traten como presas o víctimas fáciles en la calle, o cuando siguen el código de la calle y quieren ser reconocidas como personas que saben defenderse a sí mismas y a los suyos, muestran su capacidad de agencia. Ésta, sin embargo, no se limita a las defensas o las peleas. El hecho de circular por las calles del barrio y de tener presencia en las mismas, la comunicación de afectos a los seres queridos, y las relaciones que establecen y se mantienen con los vecinos son también otras formas de crear nuevos espacios de agencia. De esta manera, al sobrellevar la casi permanente amenaza de violencia en su contexto cotidiano, también pueden expandir la agencia a otros espacios.

\section{Caso 2: mujeres migrantes en el comercio sexual}

El territorio fronterizo mexicano que colinda con Guatemala es una franja tradicional de cruce de migrantes centroamericanos. En el caso concreto de las mujeres centroamericanas, Rojas Wiesner (2007) ha documentado tres flujos migratorios de acuerdo a la actividad económica que las mujeres realizan: las agricultoras, las trabajadoras domésticas y las trabajadoras sexuales. De éstos, el de mujeres que se integran al comercio sexual es el más difícil de calcular, no solo por el estatus migratorio de las sujetos, sino también por el estigma social que marca dicha actividad y que obliga a que muchas centroamericanas lo realicen de manera clandestina. La falta de datos estadísticos confiables y las dificultades metodológicas para obtenerlos y manejarlos han sido señalados por varios autores como uno de los mayores problemas que existen para abordar los problemas de las trabajadoras sexuales y enfrentar los delitos relacionados con el comercio sexual (Agustín, 2006; UNESCO s. f.; Weitzer, 2007, 2010). Pese a esta carencia, en el discurso público mexicano se suele relacionar el trabajo sexual directamente con el delito de trata de personas, de tal manera que muchas veces se utilizan como sinónimos (Weitzer, 2007, 2010). Así, aunque la trata ${ }^{7}$ tiene diversas expresiones, se ha convertido a la mujer que trabaja en el comercio sexual en la víctima por antonomasia. En esta investigación no se trabajó con mujeres en situación de trata, sino con centroamericanas que se trasladaron a la frontera sur de México con el objetivo de trabajar en el comercio sexual local. ${ }^{8}$

7 Por "trata de personas" se entiende: la captación, el transporte, el traslado, la acogida o la recepción de personas, recurriendo a la amenaza o al uso de la fuerza y otras formas de coacción, al rapto, al fraude, al engaño, al abuso de poder o de una situación de vulnerabilidad o a la concesión o recepción de pago o beneficios para obtener el consentimiento de una persona que tenga autoridad sobre otra, con fines de explotación. Esta explotación incluirá, como mínimo, la explotación de la prostitución ajena $\mathrm{u}$ otras formas de explotación sexual, los trabajos o servicios forzados, la esclavitud o las prácticas análogas, la servidumbre o la extracción de órganos (ONU, 2004).

8 Se llevó a cabo observación participante y entrevistas con seis mujeres (tres con cada una) con las que se construyeron sus historias de vida. Las informantes eran migrantes irregulares provenientes de Centroamérica, con edades 
En México, el trabajo sexual no está criminalizado, ni reconocido por la ley federal. Sin embargo, cada Estado tiene la potestad de legislarlo independiente. En Chiapas, el comercio sexual está regulado, ${ }^{9}$ pero esto no implica ningún derecho de tipo migratorio y laboral para las mujeres. Lo que sí está penado es el delito de trata. Desde 2009, en Chiapas existe la Ley Estatal para Combatir, Prevenir y Sancionar la Trata de Personas. Este marco legal está directamente relacionado con la prostitución y la migración indocumentada, pues se ha utilizado especialmente para la persecución del delito de trata relacionado con la explotación sexual de mujeres migrantes indocumentadas.

En la práctica, la persecución de este delito se traduce principalmente en redadas, que lleva a cabo la policía junto a autoridades migratorias y de la jurisdicción, en establecimientos con permisos para operar (bares, zona de tolerancia y table dance). Debido a que en estos lugares se encuentra a gran parte de las mujeres que trabajan en el comercio sexual, se han perfilado como el objetivo principal de la política de rescate de víctimas de trata. Sin embargo, estos rescates, por lo que explican las mujeres, se reducen a la detención de cualquier extranjera que no tenga consigo la tarjeta sanitaria, que parezca menor de edad o que simplemente no tenga estatus migratorio regular,

entre los 23 y 32 años. Las entrevistas tuvieron por objetivo principal indagar en las prácticas de resistencia cotidiana de las trabajadoras sexuales.

9 El marco regulatorio establece que las actividades relacionadas con el comercio sexual solo pueden llevarse a cabo en la zona de tolerancia y en ciertos establecimientos catalogados como "giros negros". Además manda a los y las trabajadoras a registrarse en la jurisdicción sanitaria, a realizarse chequeos médicos periódicos y llevar siempre consigo una tarjeta de identificación. que es la condición de la mayoría. Como resultado, muchas son detenidas discrecionalmente, obligadas a pagar multas, repatriadas o, si son catalogadas como víctimas de la trata, llevadas a albergues, aún en contra de su voluntad. Esto ilustra que las mujeres en el comercio sexual no solo son objeto de violencia perpetrada por clientes, empleadores o mafias, como lo representa el discurso público oficial; sino también, y en gran medida, por parte de las autoridades.

Sin embargo, no son pasivas ante la violencia de la que son objeto. Pese a las constricciones que les implica trabajar en el comercio sexual, estas logran maniobrar en momentos específicos para evitar o esquivar las situaciones de riesgo. Dicha capacidad, sin embargo, no implica la subversión de los sistemas que las oprimen.

A continuación se presentan extractos de entrevistas llevadas a cabo con trabajadoras sexuales que ilustran esta ambivalencia en cuatro tipos de prácticas: no quedarse solas, la negociación de servicios y cobros, huir de las autoridades y trabajar en la calle.

Para las mujeres en el comercio sexual los clientes representan la fuente de sus ingresos, al mismo tiempo que el riesgo cotidiano de sufrir algún tipo de violencia. Diariamente, cuando un cliente solicita sus servicios, las mujeres se enfrentan a una serie de decisiones: aceptarlo o no, y si lo aceptan, bajo qué condiciones y qué medidas tomar para protegerse de posibles situaciones de violencia. Una de las más habituales es que los clientes les soliciten "salida", es decir, ir con el cliente a un sitio que él decide para recibir los servicios sexuales. Algunas se niegan a este tipo de trato, pero otras aceptan, 
siempre y cuando puedan ir acompañadas. Una de las trabajadoras sexuales relató al respecto:

Hay clientes que llegan y dicen: ¿pueden ir afuera?, y a veces digo, vamos dos. Tuve una amiga, que se fue a Puebla, que a veces en la noche decía: uy, hay un cliente que quiere salir, vamos las dos. Así sí, vamos las dos, pero a unas les han pasado cosas. La otra vez mataron a una. Han matado a varias. Ése es el temor que nos da el salir afuera [...] Entonces la seguridad que sentimos de una a otra es ir juntas, nada más. Sí, porque tal vez no vamos a poder con la persona pero alguna le va a dar un palo. El problema es que [hay] muchos que llevan armas, entonces lo más [al menos] que vayamos dos, tres, pero si tiene arma... Es un riesgo que se corre (Selma, trabajadora de calle, 30 años).

Un momento crucial es la negociación de los servicios y el pago. Como relataron las mujeres, un pacto mal hecho puede significar que al final del servicio sexual el cliente no les pague o, que las agreda físicamente. Por eso, piensan que lo mejor es trabajar con clientes habituales, hombres a los que ya conocen y con los que tienen confianza. Sin embargo, cuando esto no es posible se vuelve de vital importancia dejar claro, desde un principio, cuánto cobran y qué tipo de servicio incluye ese precio. Otra trabajadora sexual de la calle explicó esta situación:

Fíjate que no me da miedo. Cuando ya son clientes uno los conoce, cuando no, yo solo le pido a Dios que me pase solo a buenas personas. Nunca, nunca, he tenido problemas con ningún cliente. Pero con la cosa de los servicios que prestas, no te creas, sinceramente a mí no me ha tocado porque me dicen:

‘-¿Cuánto cobras?

-Tanto.
-¿Qué ofreces?

-Ofrezco esto y esto, nada más, no puedo ofrecerte nada más.

-¿Segura?

-Sí.'

Porque así dicen [algunas mujeres], pero luego a la hora de la hora no [ellas] hacen nada [...]. Para convencer al hombre le dicen 'te doy esto, te doy aquí...' Y luego no hacen nada, y ahí es donde el cliente se molesta y tienen problemas (Delia, 32 años).

Una trabajadora de bar explica de similar manera que la negociación de servicios y el pago es una forma de prevenir ser agredidas:

- ¿Vos negociás con los clientes qué servicios das o hacés lo que ellos quieran?

-No. Los clientes es lo primero que preguntan y yo no les voy a mentir en una cosa que no voy a hacer, y ése es el problema que hay también. A mí cuando me preguntan:

‘¿Cuánto cobrás?

-300 .

$-¿$ Y lo menos?

-250 .

-¿Y qué haces?

-Lo normal. Sexo normal.'

Pero hay otros que te dicen que te dan tanto si hacés otras cosas en el cuarto, y hay mujeres que dicen que sí y luego no hacen nada y por eso les rompen su madre [las golpean] (Esmeralda, 32 años).

A pesar de estas situaciones habituales, a lo largo de las entrevistas con las trabajadoras sexuales las quejas principales estuvieron dirigidas a los cuerpos policiales y autoridades migratorias que las persiguen, las detienen, las multan y muchas veces las repatrían a sus países. Desde la perspectiva de las mujeres el estatus migratorio irregular y la falta 
de reconocimiento de derechos de trabajo hace que las persigan y muchas veces las signifiquen como víctimas de trata, posición desde la cual tienen escaso margen para el ejercicio de otros derechos. Cuando se preguntó sobre alguna situación de riesgo con las autoridades, Esmeralda explicó cómo se las arreglaba para huir de las redadas que se hacen en el bar donde trabaja:

La más bonita es cuando nos saca carrera Migración, ahí nos sacan a la carrera del bar. Lo chistoso es que llaman [antes] a la señora [dueña del bar] y le dicen que van a deportar y que nos saque [...]. Nosotras nos reímos, porque salimos a la carrera y ahí vemos cómo hacemos. Con sandalias, sin sandalias, a carreras por toda la orilla del río. Si nos agarran ahí sí nos deportan (Esmeralda, 32 años).

Por orden municipal está prohibido ofrecer servicios sexuales fuera de la zona de tolerancia o de los establecimientos registrados como "giros negros". Por esta razón las trabajadoras sexuales más vulnerables a las persecuciones y a ser detenidas son las que trabajan en la calle. De las informantes, dos preferían trabajar todos los días en una de las calles céntricas de Tapachula, desde aproximadamente las 10 de la mañana hasta las seis de la tarde. Haber tomado la decisión de estar en la calle, sin embargo, no las eximía del riesgo de ser perseguidas, capturadas, detenidas en estaciones policiales y repatriadas o de tener que pagar multas con dinero o servicios sexuales, como lo muestra la siguiente cita:

Pero ese día tal vez nos tocó la de perder, porque venía la patrulla [policía municipal] y nosotras estábamos en una banqueta sentadas. Se para la patrulla y no más truena la puerta de la patrulla, nosotras pegamos carrera como de aquí antes de la esquina. [...] Salieron corriendo detrás de nosotras. [...] Es que dicen que supuestamente tienen orden, pero tal vez lo que ellos quieren también es dinero. Si nos llevan tenemos que pagar la multa. Da coraje, porque uno tal vez va juntando poco a poco las monedas y de un ramplón llegan y te sacan 500 pesos. [...] Ni a los ladrones andan siguiendo como lo corren a uno. Eso es lo que da coraje (Delia, 32 años).

Pese al acoso constante de la policía, estas mujeres han encontrado en el trabajo sexual de calle una manera de evitar trabajar por las noches y desvelarse, pero además sortear la obligación que existe en los bares de tomar bebidas embriagantes con los clientes. La siguiente conversación ejemplifica las razones de una entrevistada de haber decido no registrarse en la jurisdicción sanitaria y trabajar en la calle:

Tendría que trabajar allá en la zona de tolerancia. Pero allí no va nadie y nada más por las noches. Y si uno quiere trabajar tiene que tomar. Yo tomo solita. Sí, me gusta, pero me gusta tomar, me gusta bailar, me fascina bailar, me gusta tomar, pero como le digo, cuando yo tengo ganas, no por trabajo. Si quiero dos, dos, si quiero cinco, cinco y si quiero más, más, pero ahí tengo que tomar para ganar. Nunca me ha gustado. Hay noches que llegan ahí a decirnos de muchos sitios, bares, muchas cosas similares para ir a trabajar donde vamos a ganar más, pero yo digo, voy a salir bien borracha y luego ni me voy a acordar dónde voy a dejar las fichitas que le dan a uno para poder cobrar y no (Selma, 30 años). 
Entre la victimización y la agencia en el comercio sexual

Para comprender las decisiones de muchas mujeres de migrar y trabajar en el comercio sexual es importante tener en cuenta los factores económicos, históricos y culturales que las rodean. Los relatos anteriores indican que la violencia experimentada se fundamenta en las estructuras sociales en las cuales tienen que llevar a cabo su trabajo. Pero pese a las constricciones que dichas estructuras suponen, encuentran maneras de enfrentar la violencia y sortearla. Sin embargo, en el discurso público dominante estos factores se suelen dejar de lado, y habla casi exclusivamente de las mujeres como víctimas del delito de trata que necesitan ser rescatadas de lo que hacen para vivir.

Kempadoo $(2005,2007)$ apunta cómo la representación dominante de esta víctima de trata, en la literatura académica, gubernamental y medios de comunicación, asume que las mujeres han sido coaccionadas o engañadas para moverse de sus países e integrarse al comercio sexual. Enfocar el trabajo sexual y las mujeres que lo ejercen como víctimas de una manifestación de violencia contra las mujeres resulta en una lente muy reducida para explicar la diversidad de situaciones y contextos que ellas atraviesan. Esta simplificación desvaloriza sus voces, sus decisiones y las acciones que llevan a cabo para procurarse beneficios y la consecución de sus intereses a través del uso de su sexualidad. Pero al mismo tiempo también invisibiliza las causas estructurales e históricas de las limitaciones sociales y de contexto en las que estas personas deciden moverse entre fronteras y trabajar. Por ejemplo, el estatus migratorio irregular, la falta de derecho a trabajar, las persecuciones de la policía y de autoridades migratorias para deportarlas.

\section{CONCLUSIONES: LA PERMANENTE NEGOCIACIÓN ENTRE LA VÍCTIMA Y LA AGENTE}

En su lucha por lograr una conciencia social sobre la incidencia de la violencia contra las mujeres, sus consecuencias y combatir su erradicación, el movimiento feminista ha tendido a enfatizar en su situación de victimización. No obstante, el acento en la víctima ha llevado a formar un discurso de mujer-víctima que tiende a dejar de lado la complejidad de las situaciones de violencia (entre ellas las estructuras históricas y sociales, la intersección con otras formas de opresión de raza, clase, nacionalidad, la falta de presencia del Estado), que median también en la capacidad de las mujeres de ejercer su agencia cuando intentan detener o sortear las opresiones o abusos.

Portanto, en este texto se ha intentado resaltar que más de allá de identificar una figura víctima es de utilidad resaltar la interacción que se da entre las posiciones de víctima y agente entre las cuales pueden moverse las mujeres, incluso cuando viven en condiciones socio económicas limitadas y desiguales, y se encuentran en situaciones en las que puede vulnerarse su integridad. Destacar la figura de víctima puede llevar a olvidar que esas mismas mujeres también realizan elecciones en medio de las complejas situaciones donde el maltrato, la violencia, el irrespeto a sus derechos 
y la precariedad de su situación económica, entre otras, muchas veces coexisten.

Los ejemplos anteriormente relatados permiten destacar que ser sujetos de múltiples opresiones y conservar la capacidad de agencia no son factores excluyentes, e incluso pueden manifestarse de manera concurrente. Las mujeres que optan por usar violencia o por trabajar en el comercio sexual no lo hacen como una respuesta desesperada o de total coerción, ni por una disminución o falta de capacidad de tomar decisiones conscientes y razonables. En sus decisiones y comportamientos cotidianos coexisten las situaciones de riesgo y opresión, pero dentro de ellos también logran ciertos beneficios y consecución de intereses como protección, respeto, reputación, autonomía económica y movilidad social. Así, sus acciones están sujetas en gran medida a las estructuras que las mantienen en desventaja, como la falta de protección social o legal del Estado. Esas acciones no tienen el objetivo, muchas veces pretendido desde otros sectores, de cambiar o subvertir el sistema de violencia del que son objeto, sino de ir sorteando las dificultades que enfrentan. Todas estas mujeres pueden tener otros propósitos legítimos, relacionados con su protección, la cobertura de sus necesidades básicas o con su situación legal y la de sus seres queridos.

Las conductas resaltadas en los ejemplos mostrados no corresponden a formas convencionales o aceptadas para las mujeres: en la sociedad más amplia, la violencia y el trabajo sexual no se consideran moralmente correctos, mucho menos para una mujer. Sin embargo, en las situaciones que ellas viven, comportarse de manera violenta, por ejemplo, no significa que actúen de manera inadecuada, que quieran verse masculinas o que sean malas. En el caso de las trabajadoras del sexo, no las convierte en sujetos pasivos e inocentes o con falsa conciencia. De la misma manera, al no ser la víctima ideal — porque se usa violencia para defenderse o porque se recurre conscientemente al trabajo sexual- se corre el riesgo de estigmatizarlas, de ignorar las situaciones en las que son víctimas y su necesidad de una intervención social mayor para que efectivamente puedan mejorar las condiciones en las que viven.

Las valoraciones morales dominantes alrededor de las conductas que se alejan de lo permitido a las mujeres y de la imagen de víctima pueden obstaculizar el distinguir a estas mujeres como agentes y con necesidades de atención a sus condiciones precarias de vida. Así, muchas feministas rehúsan ahondar en el fenómeno de la violencia ejercida por las mujeres por el temor de que sea usado en contra de las mujeres o del movimiento feminista. $\mathrm{O}$ rechazan reconocer el uso de la sexualidad como recurso económico, por contraponerse a conceptualizaciones occidentales sobre el cuerpo y la sexualidad femeninos como exclusivos para el amor y relaciones románticas. En esa línea han surgido discursos y prácticas que: a) oscurecen las diferencias en las experiencias de las mujeres; $b$ ) ignoran a aquellas que no cumplen las características identitarias de la "víctima"; y c) justifican prácticas de tutela o exclusión que desconocen a las mujeres como personas capacitadas para manejar su vida y tomar decisiones sobre ella. 
Lejos de emitir una valoración sobre la violencia practicada por mujeres o el trabajo sexual, y sin desconocer la necesidad de atención y erradicación de las distintas formas de violencia y abusos contra las mujeres, se ha querido destacar las decisiones, acciones o estrategias tomadas por algunas mujeres y que les han sido útiles para enfrentar las problemáticas que viven cotidianamente. En muchos de los contextos o de sus interacciones sociales no están presentes las normas sociales convencionales, y por tanto, desde afuera, no puede exigirse una respuesta convencional. Tal es el caso de las calles de los barrios populares bonaerenses o de los lugares de destino de migrantes irregulares sin posibilidades de regularizar su estatus migratorio y laboral en el sur mexicano ¿Esas mujeres deben entonces acatar las normas que les mandan no ser violentas, ser dóciles y esperar que el auxilio llegue? ¿Deben ellas permanecer en sus países o buscar un organismo que venga a rescatarlas del crimen de trata del que se asume a priori que han sido objeto? Donde las condiciones y normas son otras y donde ni las normas convencionales ni las instituciones sociales las protegen, las mujeres deben responder por ellas mismas, encontrar alternativas con los pocos recursos de los que disponen. No obstante, reconocer la capacidad de agencia de estas mujeres no implica desconocer las múltiples opresiones y los riesgos a los que siguen expuestas, sino únicamente que estas mujeres son capaces de lidiar en medio de situaciones adversas, a las cuales sigue existiendo una necesidad de dar respuesta. Este artículo, por tanto, no es una celebración de sus pequeños "triunfos" en medio de la adversidad; al contrario, se busca dar un reconocimiento a las estrategias encontradas por estas mujeres para no encerrarlas en la categoría "víctima" y también llamar la atención sobre la necesidad de tomar conciencia de las circunstancias que las llevan a esas acciones, para orientar medidas y políticas públicas que conduzcan a mejorar sus condiciones de vida. a

\section{AGRADECIMIENTOS}

Las autoras agradecen a las entrevistadas que participaron en las dos investigaciones y que han servido de insumo para escribir este artículo. Sin su tiempo y confianza para relatarnos sus experiencias no hubiese sido posible documentar los planteamientos aquí expresados.

También extienden sus agradecimientos a las personas que revisaron el artículo. Sus valiosas sugerencias permitieron enriquecerlo y fomentar la discusión en estos temas. 


\section{BIBLIOGRAFÍA}

Agustín, Laura (2003), "Forget Victimization: Granting Agency to Migrants", en Development, vol. 46, núm. 3, pp. 30-36.

Agustín, Laura (2006), “The Disappearing of a Migration Category: Migrants Who Sell Sex”, en Journal of ethnic and migration studies, vol. 32, núm. 1, pp. 29-47.

Allen, Amy (2001), "Pornography and Power”, en Journal of Social Philosophy, vol. 32, núm. 4, pp. 512-531.

Allen, Amy (2008), "Power and the Politics of Difference: Oppression, Empowerment, and Transnational Justice”, en Hypatia, vol. 23, núm. 3, pp. 156-172.

Anderson, Elijah (2000), Code of the street: Decency, Violence, and the Moral Life of the Inner City. Nueva York, W. W. Norton and Company.

Batchelor, Susan (2005), "'Prove me the bam!': Victimization and agency in the lives of young women who commit violent offences", en The Journal of Community and Criminal Justice, vol. 52, núm. 4, pp. 358-375.

Beltrán, María Antonieta (2013), “Construcciones localizadas de la identidad de género: usos legítimos e ilegítimos de la fuerza en mujeres de barrios populares urbanos”. Buenos Aires, Argentina, Universidad de Buenos Aires, tesis de doctorado en Ciencias Sociales.

Bergalli, Roberto y Encarna Bodelón (1992), "La cuestión de las mujeres y el derecho penal simbólico", en Anuario de Filosofía del Derecho, núm. 9, pp. 43-74.

Brewer, Rose (1999), “Theorizing Race, Class and Gender: The New Scholarship of Black Feminist Intellectuals and Black Women's Labor", en Race, Gender and Class, vol. 6, núm. 2, pp. 29-47.

Brunatti, Olga (2011), "La judicialización de los conflictos intrafamiliares en el fuero penal bonaerense. Modelos interpretativos de violencia familiar y nociones nativas de la categoría víctima", en Theophilos Rifotis y Natalia Castelnuovo (comps.), Antropología, violencia y justicia. Repensando 
matrices de la sociabilidad contemporánea en el campo del género y de la familia. Buenos Aires, Antropofagia, pp. 125-154.

Butler, Judith (1999), El género en disputa. El feminismo y la subversión de la identidad. Barcelona, Paidós.

Butler, Judith (2001), Mecanismos psíquicos del poder. Teorías sobre la sujeción. Madrid, Universidad de Valencia.

Campbell, Anne (1993), Men, Women, and Aggression. From Rage in Marriage to Violence in the Streets. How Gender Affects the Way We Act. New York, Basic Books.

Campbell, Anne (1999), "Self Definition by Rejection: The Case of Gang Girls", en Meda Chesney-Lind y John Hagedorn (eds.), Female Gangs in America: essays on Girls, Gangs and Gender. Chicago, Lakeview Press, pp. 100-117.

Chesney-Lind, Meda y Lisa Pasko (2004), The Female Offender. Girls, Women, and Crime. California, Sage.

Chesney-Lind, Meda y Michele Eliason (2006), "From invisible to incorrigible: The demonization of marginalized women and girls”, en Crime Media Culture, vol. 2, pp. 29-47.

Chesney-Lind, Meda y Nikki Jones (2010), “Introduction”, en Meda Chesney-Lind y Nikki Jones (eds.), Fighting for Girls. New Perspectives on Gender and Violence. New York, Suny Press.

Christie, Nils (1986), "The Ideal Victim”, en Ezzat Fattah (ed.), From Crime Policy to Victim Policy: Reorienting the Justice System. London, The Macmillan Press, pp. 13-40.

Connell, Patricia (1997), "Understanding Victimization and Agency: Considerations of Race, Class and Gender”, en Political and Legal Anthropology Review, vol. 20, núm. 2, pp. 115-143.

Cuarta Conferencia Mundial de la ONU sobre la Mujer (1995), Declaración y la Plataforma de Acción de Pekín.

Dignan, James (2004), Understanding victims and restorative justice. New York, McGraw-Hill International. 
Dunn, Jennifer (2005), “"Victims” and 'survivors': Emerging vocabularies of motive for 'battered women who stay",, en Sociological Inquiry, vol. 75, núm. 1, pp. 1-30.

Dunn, Jennifer y Melissa Powell-Williams (2007), "Everybody Makes Choices: Victim Advocates and the Social Construction of Battered Women's Victimization and Agency", en Violence Against Women, vol. 13, núm. 10, pp. 977-1001.

Emirbayer, Mustafa y Ann Mische (1998), "What is Agency?”, en The American Journal of Sociology, vol. 103, núm. 4, pp. 962-1023.

García Selgas, Fernando y Elena Casado Aparicio (2010), Violencia en la pareja: género y vínculo. Madrid, Talasa Ediciones.

Hartsock, Nancy (1992), "Foucault sobre el poder: una teoría para las mujeres”, en Linda Nicholson (comp.), Feminismo y postmodernismo. Buenos Aires, Feminaria, pp. 30-52.

Hollander, Jocelyn (1992), "Vulnerability and Dangerousness: The Construction of Gender through Conversation about Violence”, en Gender and Society, vol. 15, núm. 1, pp. 83-109.

Hollander, Jocelyn (2002), "Resisting Vulnerability: The Social Reconstruction of Gender in Interaction", en Social Problems. Berkeley, vol. 49, núm. 4, pp. 474-496.

Hollander, Jocelyn (2005), “Challenging Despair: Teaching about Women's Resistance to Violence”, en Violence Against Women, vol. 11, núm. 6, pp. 776-791.

Jones, Nikki (2010), Between Good and Ghetto: African American Girls and Inner City Violence. New Jersey, Rutgers University Press.

Kapur, Ratna (2002), “The Tragedy of Victimization Rhetoric: Resurrecting the 'Native' Subject in International/Post-Colonial Feminist Legal Politics”, en Harvard Human Rights Journal, vol. 15, núm. 1, pp. 1-37.

Kempadoo, Kamala (2005), "Mudando o debate sobre o tráfico de mulheres”, en Cadernos Pagu, vol. 25, pp. 55-78. 
Kempadoo, Kamala (2007), “The war on human trafficking in the Caribbean”, en Race and Class, vol. 49, núm. 2, pp. 79-85.

Krantz, Gunilla y Claudia Garcia-Moreno (2005), "Continuing professional Education. Violence against Women”, en Journal of Epidemiology and Comunity Health, vol. 59, pp. 818-821.

Lugones, María (2008), “Coloniality and Gender”, en Tabula Rasa, vol. 9, Julio-Diciembre, pp. 73-112.

Mahmood, Saba (2001), "Feminist Theory, Embodiment, and the Docile Agent: Some Reflections on the Egyptian Islamic Revival”, en Cultural Anthropology, vol. 16, núm. 2, pp. 202-236.

Maqueda, María Luisa (2006), "La violencia de género. Entre el concepto jurídico y la realidad social”, en Revista Electrónica de Ciencia Penal y Criminología, vol. 8, núm. 2, pp. 1-13.

McClintock, Anne (1993), “Sex Workers and Sex Work: Introduction”, en Social Text, vol. 37, pp. 1-10.

Miller, Jody (2001), One of the Guys. Girls, Gangs and Gender. New York, Oxford University Press.

Mohanty, Chandra (1991), "Under Western Eyes: Feminist Scholarship and Colonial Discourses”, en Chandra Mohanty, Ann Russo y Lourdes Torres (eds.), Third World Women and the Politics of Feminism. Bloomington, Indiana University Press, pp. 51-80.

Mohanty, Chandra (2003), Feminism Without Borders: Decolonizing Theory, Practicing Solidarity. Durham, Duke University Press.

Nayak, Meghana y Jennifer Suchland (2006), “Gender Violence and Hegemonic Projects”, en International Feminist Journal of Politics, vol. 8, núm. 4, pp. 467-485.

Ness, Cindy (2010), Why Girls Fight. Female Youth Violence in the Inner City. New York, New York University Press.

ONU (Organización de las Naciones Unidas) (2004), Convención contra la delincuencia organizada transnacional y sus protocolos. New York.

Pateman, Carole (1995), El contrato sexual. Barcelona, Anthropos. 
Puex, Nathalie (2003), "Las formas de violencia en tiempos de crisis: una villa miseria en el conurbano bonaerense", en Alejando Isla y Daniel Míguez (coords.), Heridas Urbanas. Violencia delictiva y transformaciones sociales en los noventa. Buenos Aires, De las Ciencias, pp. 35-70.

Randall, Melanie (2004), “Domestic Violence and the Construction of 'Ideal Victims': Assaulted Women's 'Image Problems' in Law', en Saint Louis University Public Law Review, vol. XXIII, pp. 107-154.

Ravelo Blancas, Patricia (2001), "La clase y el género, ¿dos conceptos irreconciliables a finales del milenio? Notas para un debate", en Nueva Antropología, vol. XVIII, núm. 59, México, pp. 145160.

Rojas Wiesner, Martha (2007), “Mujeres y migración en la frontera sur de México”, en Les Cahiers ALHIM, vol. 14, pp. 147-167.

Sánchez, Lisa (1999), "Sex, Law and Paradox of Agency and Resistance in the Everyday Practices of Women in the 'Evergreen' Sex Trade”, en Henry Stuart y Milovanovic, Dragan (eds.), Constitutive Criminology at Work: Applications to Crime and Justice. Albany, State University of New York Press, pp. 39-66.

Smolej, Mirka (2010), "Constructing ideal victims? Violence narratives in Finnish crime-appeal programming", en Crime, Media, Culture, vol. 6, pp. 69-85.

Suárez-Navaz, Liliana, Emma Martín y Rosalva Hernández Castillo, (2008a), Feminismos en la antropología: nuevas propuestas críticas. País Vasco, Donostia, Ankulegi Antropología Elkartea.

Suárez-Navaz, Liliana y Rosalva Hernández Castillo (2008b), Descolonizando el feminismo: teorías y prácticas desde los márgenes. Madrid, Editorial Cátedra.

Sussman, Erika (2008), “Agency / Autonomy of Battered Woman”, en Claire Renzetti y Jeffrey Edleson (eds.), Encyclopedia of interpersonal violence. Thousand Oaks, Sage, pp. 15-16.

UNESCO (s/f), Trafficking Statistics Project, consultado el 3 de octubre de 2015, URL: http:// humantrafficking.org/links/83. 
Weitzer, Ronald (2007), “The Social Construction of Sex Trafficking: Ideology and Institutionalization of a Moral Crusade", en Politics \& Society, vol. 35, núm. 3, pp. 447-475.

Weitzer, Ronald (2010), “The Mythology of Prostitution: Advocacy Research and Public Policy”, en Sexuality Research and Social Policy, núm. 7, pp. 15-29.

Weseley, Jennifer (2006), “Considering the Context of Women's Violence. Gender, Lived Experiences, and Cumulative Victimization", en Feminist Criminology, vol. 1, núm. 4, pp. 303-328.

Young, Iris Marion (2011), Justice and the Politics of Difference. United Kingdom, Princeton University Press.

Fecha de recepción: 17 de junio de 2015

Fecha de aceptación: 11 de noviembre de 2015 